\title{
The glass ceiling: Career barriers for female employees in the ready made garments
} (RMG) industry of Bangladesh

\begin{abstract}
The primary objective of the study is to identify the glass ceiling issues and career barriers for female employees to access into the leadership positions in Ready-Made Garments (RMG) organisations in Bangladesh. This exploratory study used semi-structured face-to-face interview methods for data collection. The study conducted only 10 interviews among with 10 main questions concerning the glass ceiling issues and career barriers with the female employees from 5 biggest RMG organisations. After consecutive analysis to all transcripts of the interviews, three ideological approaches such as organisational culture, social culture and lack of career encouragers are identified as the main barriers for females to get into the leadership positions. The study includes discussion on how organisations can facilitate the process of females' advancement into the leadership positions.
\end{abstract}

Keyword: Glass ceiling; Career barriers; RMG; Females; Leadership positions 